\title{
Inhalt
}

Dank - V

Juliane Schröter, Susanne Tienken und Yvonne Ilg

Linguistische Kulturanalyse

Eine Einführung -1

Arnulf Deppermann

„s hat sicherlich auch öh (0.4) kultuRELle (0.8) öh n kultuRELlen hintergrund“

Kultur in der alltäglichen Interaktion -29

Sybille Krämer

Sprachgebräuche jenseits des Sprechens

Oder: über die ,stumme Epistemologie‘ der inskribierten Fläche - 51

Helmuth Feilke

Konservierung und die kulturelle Kreativităt der Sprache - 69

Jakob Tanner

Binäre Codes und komplexes Denken

Digital Humanities und Geschichtswissenschaft - 91

Damaris Nübling

Onomastische Kulturanalyse

Was uns die Muster ostfriesischer Personennamen über die ostfriesische

Kultur berichten (könnten) 111

Lann Hornscheidt

Sprachliche Gewalt differenzieren

Plädoyer für eine kulturanalytische diskriminierungskritische

Sprachwissenschaft -139

Ulla Kleinberger

Phraseologische Textvernetzung - online

Dialogisches und intertextuelles Potential in Online-Debattenforen — 171

Britt-Marie Schuster

Meines Vaters Haus und des Trainers Credo

Eine kulturanalytische Untersuchung pränominaler Genitivattribute -195 
Doris Tophinke

Konstruktionale Aspekte schriftkultureller Autozentrierung im Spätmittelalter Zu einer markanten sprachlichen Neuerung in der Buchführung der Hansekaufleute des 14. Jahrhunderts - 219

Christa Dürscheid und Horst J. Simon

Auf dem Weg zu einer pluriarealen Variantenpragmatik -245

Susanne Günthner

,Kultur-in-kommunikativen-Praktiken

Kommunikative Praktiken zur Übermittlung schlechter Nachrichten in onkologischen Aufklärungsgesprächen - 269

Heiko Hausendorf

\section{Das Ferienwetter auf der Ansichtskarte}

Ein Wetterbericht im Schnittpunkt von Textlinguistik, Medienlinguistik und Korpuspragmatik 293

Ulla Fix

Kulturbezogene Textlinguistik und kulturanalytische Textstilistik

Zwei Texte vom Ende des langen 19. Jahrhunderts - 323

Martin Luginbühl und Stefan Hauser

Journalistische Kulturen aus der Perspektive einer kulturanalytischen

Medienlinguistik -347

Heidrun Kämper

Kulturlinguistik und sprachliche Sozialgeschichte

Überlegungen zur Operationalisierung - 371

David Eugster

„Political Correctness“ in der Schweiz

Geschichte eines semantischen Schweizer Taschenmessers _- 393

Register -413 